Etnográfica

Revista do Centro em Rede de Investigação em

Antropologia

vol. $23(2) \mid 2019$

Vol. $23(2)$

\title{
Ontologia da confusão: Exu e o Diabo dançam o "Samba do Crioulo Doido"
}

Ontological confusion: Eshu and the Devil dance to the "Samba of the Black

Madman"

\section{Moisés Lino e Silva}

\section{(2) OpenEdition}

Journals

Edição electrónica

URL: https://journals.openedition.org/etnografica/6938

DOI: 10.4000/etnografica.6938

ISSN: 2182-2891

\section{Editora}

Centro em Rede de Investigação em Antropologia

\section{Edição impressa}

Data de publição: 1 junho 2019

Paginação: 515-532

ISSN: 0873-6561

\section{Refêrencia eletrónica}

Moisés Lino e Silva, "Ontologia da confusão: Exu e o Diabo dançam o "Samba do Crioulo Doido"», Etnográfica [Online], vol. 23 (2) | 2019, posto online no dia 25 junho 2019, consultado o 19 janeiro 2022. URL: http://journals.openedition.org/etnografica/6938; DOI: https://doi.org/10.4000/etnografica.6938

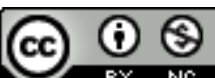

Etnográfica is licensed under a Creative Commons Attribution-NonCommercial 4.0 International License. 


\section{Ontologia da confusão: Exu e o Diabo dançam o "Samba do Crioulo Doido"}

\section{Moisés Lino e Silva}

Argumenta-se que repertórios de saberes "religiosos" facilitam o reconhecimento e a compreensão de uma grande variedade de instâncias (ontológicas) de confusão. O método utilizado na investigação é etnográfico e recursivo. Parte da confusão que se manifesta na própria capacidade de reconhecer uma confusão deriva justamente da condição de que não há posição epistemológica fixa ou neutra para servir como base a partir da qual seria possível arbitrar com imparcialidade sobre a existência de confusões enquanto formas imanentes. Na tentativa de entender melhor os modos em que a confusão existe na vida diária de alguns amigos na Rocinha, descrevo e analiso eventos que vivi durante uma festa de Exu em um terreiro de umbanda. Discuto, ainda, episódios vividos com vizinhos evangélicos na favela. Discorro sobre as lutas e os conflitos de poder que asseguram ou negam a existência e o reconhecimento de confusões diversas: por exemplo, no campo da sexualidade, das doutrinas religiosas e dos conflitos de classe. Demonstro que o poder de perturbação que Exu e Pombagira oferecem contra uma ordem social opressora torna-se bastante importante em situações de discriminação. Sugere-se que parte da dimensão política que informa atos de reconhecimento da confusão enquanto forma específica é revelada ao interrogarem-se e confundirem-se contextos de ordem contra os quais "uma confusão" pode surgir.

PALAVRAS-CHAVE: confusão, Exu, favela, ontologia, religião.

Ontological confusion: Eshu and the Devil dance to the "Samba of the Black Madman" - Religious grammars of confusion may enable the recognition and understanding of a wide variety of other (ontological) forms of confusion in the daily life of different groups living in Favela da Rocinha, Rio de Janeiro. The method used in this investigation is ethnographic and recursive. Part of the confusion manifested in the capacity to recognise "a confusion" derives exactly from the fact that there is no fixed or neutral epistemological position that would serve as a basis to decide accurately about the existence of confusion as a form. I describe and analyse particular events that I experienced during an Afro-Brazilian (Umbanda) religious celebration and other more quotidian episodes with a different group: my Evangelical friends. What are the struggles and conflicts of power that warrant the existence of certain confusions? What confusions would normative sexual, religious and class-based orders rather prevent? I argue that the disruptive power that Eshu and Pombagira offer against an oppressive social order is part of the political dimension that informs acts of recognition of confusion as a form, revealed when we interrogate and confuse the context of order against which "a confusion" may emerge.

KEYWORDS: Brazil, confusion, favela, ontology, religion.

LINO E SILVA, Moisés (moises.lino@ufba.br) - Programa de Pós-Graduação em Antropologia, Universidade Federal da Bahia (UFBA), Brasil. 


\section{BECOS DE CONFUSÃO}

Um rato gordo passa sobre nossas cabeças, equilibrando-se precariamente em um dos muitos fios que fazem parte da gigantesca rede de cabos aéreos que conecta milhares de casas na favela: trazendo eletricidade, serviço de telefone, conexão à Internet e sinal de TV para muitas delas. ${ }^{1}$ Poucas pessoas diriam compreender como exatamente o emaranhado de fios funciona, em meio à bagunça de diferentes formas, cores, tamanhos e utilidades dos componentes - complexidades entrelaçadas (figura 1). Um amigo meu, um eletricista sem muita formação técnica, tece alguns comentários sobre a possível ordem do que parece uma confusão total para aqueles que não compreendem o arranjo de fios na favela da Rocinha. Ele diz, por exemplo, que mais de metade de todos os fios são "conexões ilegais" (também conhecidas como "gatos"). O eletricista acrescenta também que outra grande parte dos fios não funciona mais, são fios muito velhos e já não transmitem qualquer carga ou sinal. Como essas conexões antigas não são removidas da rede e novas conexões emergem todos os dias, o emaranhado como um todo tende a crescer constantemente. Como resultado, a cada dia a malha aérea impede cada vez mais a passagem da luz solar nas vielas estreitas (becos) utilizadas por milhares de pessoas como principal meio de circulação de pedestres e motos na favela.

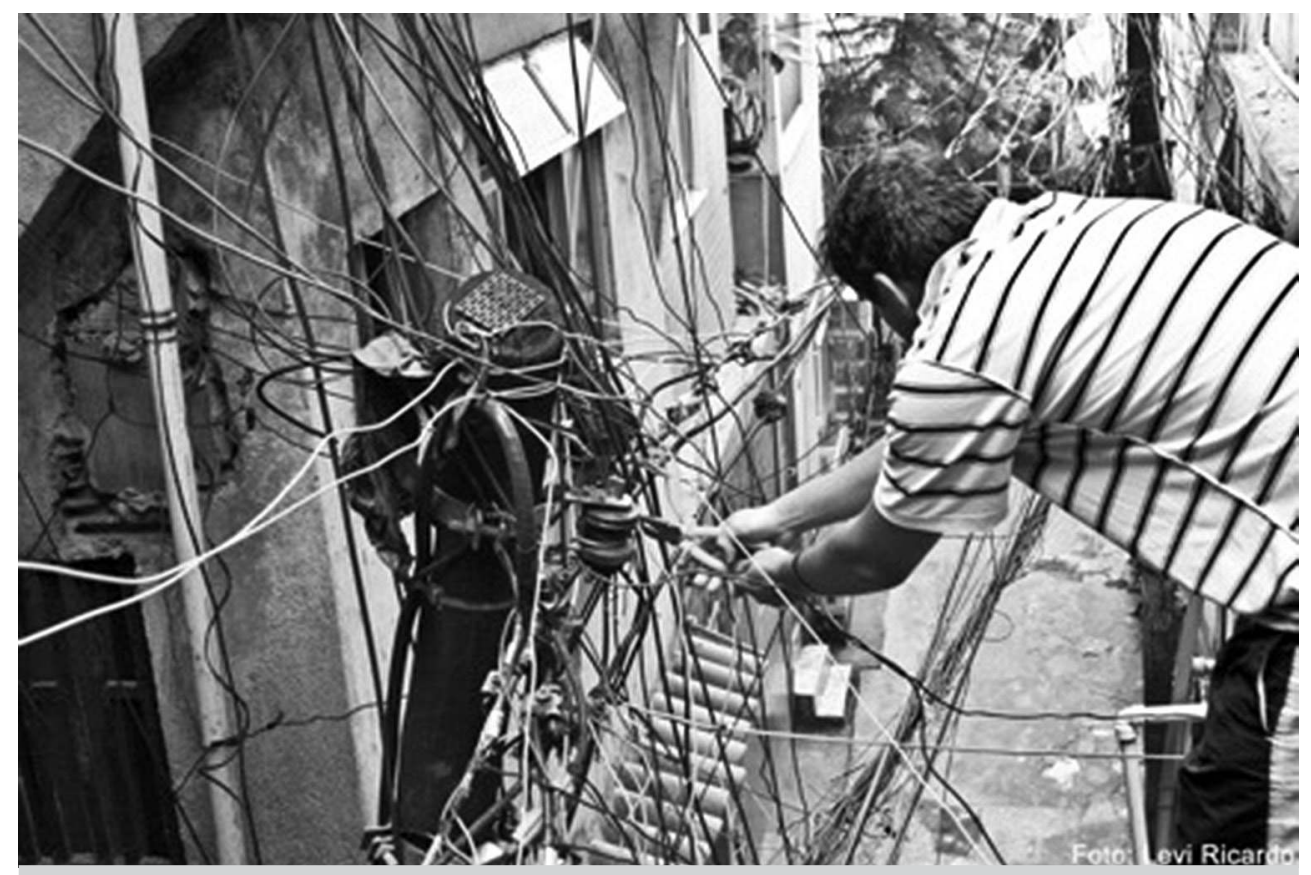

Figura 1 - Uma confusão de cabos aéreos na favela da Rocinha. Foto: Levi Ricardo. 
No meio de uma multidão barulhenta, passando por um dos becos mais movimentados da Rocinha, percebo um menino de cerca de 12 anos que havia disparado a correr, empurrando e batendo em todos que estavam na frente dele. Outra criança, muito mais nova, seguia a primeira, aproveitando o espaço que o mais alto criava enquanto ia empurrando o pessoal. De repente, começamos a ouvir, no meio da multidão, barulhos estranhos vindos de algum tipo de objeto pesado batendo repetidamente contra o chão. Quase todos os presentes no beco naquele exato momento pararam para procurar onde estava acontecendo o evento. Começaram a ficar mais quietos, procurando nervosamente pistas sobre o que estava havendo. Meus amigos que estavam sentados comigo no chão do beco, sobre folhas usadas de jornal, levantaram-se e logo em seguida colocaram-se nas pontas dos pés, tentando não perder nenhum movimento de vista.

Samira então gritou: "Olhe lá! Uma confusão lá!" Meus olhos procuraram o que ela tinha acabado de reconhecer, mas todo o beco estava tão cheio que não parecia me fornecer um fundo ideal para identificar qualquer confusão em particular. No entanto, com o passar do tempo, começou a surgir um vazio em torno de um homem de cabelos brancos e barbas longas, que carregava um grande saco de plástico preto na mão esquerda e um grande cacete de madeira na mão direita. Ele tinha suas roupas rasgadas e nenhum de seus olhos se abria completamente. Obviamente, aquele senhor não conseguia enxergar muito bem ao redor dele; entretanto, insistia em continuar golpeando violentamente em todas as direções, quase sempre contra o ar, na esperança de que em algum momento ele conseguisse acertar algo, ou alguém, além do chão. Algumas pessoas começaram a fugir rapidamente do beco e eu estava me preparando para fazer o mesmo. Samira então segurou meu braço e disse: "Calma, isso vai acabar em breve!" Ela sabia que o velho sofria de deficiência visual e alguns meninos costumavam se divertir chutando esse senhor pelas costas e depois fugindo para se esconder dele. Muito agitado, o velho costumava responder com ataques de fúria. Depois de algum tempo golpeando com o cacete de madeira, ele costumava ficar muito cansado e voltava para o mesmo lugar onde dormia todas as noites, naquele mesmo beco lotado e, ao mesmo tempo, sombrio.

\section{FORMAS, EXISTÊNCIAS E REPERTÓRIOS}

Este artigo propõe uma reflexão sobre a confusão enquanto forma cotidiana entre os moradores da favela da Rocinha, uma das maiores favelas do Rio de Janeiro. Como esses moradores, com quem eu vivi por quase dois anos, reconhecem "uma confusão"? No sentido particular de uma forma reconhecível, a confusão pode assumir uma existência muito concreta: a forma de certas situações, condições, sentimentos e práticas da vida diária. No entanto, $\mathrm{o}$ ato de reconhecer uma confusão não parece ser neutro e nem absolutamente 
determinado pelas circunstâncias da vida na favela. O que pode ser entendido como uma confusão sombria também pode revelar muito sobre a história, as lutas e as condições de vida desse lugar, cada vez mais encoberto por um emaranhado de fios (figura 1), que ao mesmo tempo conecta e confunde. O que é preciso para reconhecer e compreender a confusão na favela?

Relatos de antropólogos momentaneamente confusos durante o trabalho de campo não são incomuns. No entanto, há momentos em que o mundo parece estar confuso para todos. Como pessoas diferentes desembaraçam seus fios e encontram seus caminhos diante das confusões da vida depende de muitos fatores. Neste texto, exploro como formas distintas de conhecimento influenciam a maneira como moradores da Rocinha vivenciam e lidam com a confusão em suas experiências diárias. Particularmente, argumento que há uma inflexão entre vivências que poderiam ser consideradas "religiosas" e o reconhecimento da existência (ontológica) de confusões em domínios que incluem e, ao mesmo tempo, ultrapassam o "religioso". Apresento ainda algumas consequências dessa inflexão no que tange ao julgamento moral atribuído às confusões na favela.

Não é de surpreender que o próprio ato de reconhecer a existência da confusão sob uma forma definida pareça estar necessariamente ligado a perspectivas específicas, que fornecem as condições de possibilidade para tal ato de reconhecimento ocorrer. No entanto, considero também que a dependência do contexto não é uma explicação suficiente. Não vou argumentar que é um contexto fixo que permite a determinação da existência de confusão sob uma forma particular. Em vez disso, gostaria de considerar como o ato de reconhecer a confusão enquanto forma ontológica imanente (e que existe em um determinado lugar e tempo) implica uma diferenciação mínima entre essa forma singular e outras formas consideradas como parte do contexto (background). O método utilizado para minha investigação é etnográfico e recursivo, trabalhado para abordar uma questão mais ampla: de que maneira diferentes formas de conhecimento afetam diferentes entendimentos ontológicos da confusão na vida quotidiana?

Comecei o meu trabalho de campo reconhecendo mais facilmente as confusões generalizadas na Rocinha: o caótico sistema de trânsito, a coleta de lixo precária, a densidade hipnotizante da vida nas ruas e tantas outras. Entretanto, tinha maiores dificuldades em reconhecer formas mais específicas e precisas de confusão. Levei algum tempo para adquirir o conhecimento necessário para determinar quando formas de confusão mais específicas começavam a surgir na favela. Em certo sentido, tive que aprender o que poderia ser chamado de uma gramática de diferenciação de confusões. No entanto, ao morar na Rocinha, aprendi também que essa gramática não é nem homogênea nem circunscrita. Ao contrário, ela é tão complexa e fluida enquanto forma de conhecimento quanto complexos e fluidos são os grupos de pessoas que vivem na Rocinha. Parte da confusão inerente à capacidade de reconhecer "uma confusão" seria 
derivada exatamente do fato de que não há uma posição epistemológica fixa ou neutra para servir de base a partir da qual arbitrar com precisão a existência da confusão como forma emergente.

Experiências de liminaridade e transformações ontológicas são parte importante das chamadas "experiências religiosas" (van Gennep 1960; Turner 1967). Como tal, argumento que tal domínio atua como locus privilegiado dentro do qual a confusão ontológica é ao mesmo tempo produzida, testada e transformada em outras formas de conhecimento. Numa tentativa de compreender melhor o modo como a confusão existe na vida cotidiana das pessoas, descrevo e proponho uma análise das confusões específicas que experimentei durante um ritual de umbanda, que ocorreu durante o período em que morei na favela. Argumento que a existência de Exu como um tipo particular de "deus das confusões" na cosmologia das religiões afro-brasileiras tem consequências diretas para o entendimento da confusão no cotidiano da Rocinha, especialmente em contraste com as experiências dos meus amigos evangélicos que também vivem por lá, mas acreditam em um único Deus, e que não é do tipo trickster.

\section{EXU E POMBAGIRA DANÇAM NO ALTO DO MORRO}

Este episódio envolve, principalmente, moradores da favela autoidentificados como membros de um grupo queer chamado PAFYC. ${ }^{2}$ Em sua maioria adolescentes, esses moradores frequentavam regularmente terreiros de umbanda e quimbanda na Rocinha. Embora houvesse reclamações aqui e ali sobre o número cada vez menor de espaços para cultos de matriz africana na favela, eu ainda consegui visitar um bom número de terreiros durante o tempo em que morei na Rocinha. O segundo grupo de moradores que vai figurar no meu argumento é constituído por evangélicos neopentecostais, que eram em sua maioria meus vizinhos na favela e constantemente me convidavam para os cultos que organizavam e dos quais participavam com fervor.

Havia um número consideravelmente maior de igrejas evangélicas na comunidade do que terreiros em 2009. Na companhia dos meus vizinhos pentecostais (em geral, mais adultos e idosos), participei de vários cultos evangélicos durante meu campo em 2009 e 2010. Eu tinha conhecido a maioria dos amigos com quem eu frequentava os rituais de candomblé, umbanda e quimbanda na Rocinha, principalmente, através de afinidades queer. ${ }^{3}$ Esse fato marca uma

2 P., A., F., Y. e C. eram as iniciais dos nomes dos fundadores desse grupo de amigos adolescentes. Quando os conheci, o número de membros já estava nas dezenas. Em comum, identificavam-se através de uma série de categorias não normativas de gênero e sexualidade: "viados", "bichas", "monas", "flex", "bi", "sapatas", “travas”, dentre outras.

3 Para uma discussão mais elaborada sobre a relação de sexualidades não normativas e o candomblé, ver, por exemplo, Van de Port (2007). 
diferença significativa entre os dois grupos: os evangélicos orgulhavam-se de seguir (ou, ao menos, tentar seguir) estritas normas e ordenamentos estabelecidos por Deus, pela Bíblia e pela comunidade da Igreja. Esses ordenamentos pretendiam regrar tanto as vidas íntimas desses evangélicos quanto as relações mais amplas deles com o mundo. Nesse sentido, mostravam-se orgulhosos de serem normativos. Em contrapartida, os membros do grupo PAFYC eram amplamente não normativos, não apenas em termos de gênero e sexualidade, mas também em termos de suas próprias práticas religiosas. ${ }^{4}$ As interseccionalidades entre religião, gênero e sexualidade apresentam-se como formações importantes, que atuam, muito evidentemente, na contestação de fronteiras normativas de gênero e para celebrar identidades de gênero não normativas. ${ }^{5}$

Depois da distração momentânea oferecida pelo episódio das crianças abusando do velho senhor, a conversa com meus amigos do PAFYC voltou ao ponto onde a havíamos deixado: a festa de umbanda que começaria pouco depois da meia-noite, em uma casa localizada no alto da colina, perto de uma grande caixa-d'água, já adentrando uma pequena floresta que havia sobrevivido à urbanização maciça da área. Minha amiga Samira era uma das pessoas mais animadas com o evento: "Vai ser babado! Vai ser incrível!" Havia sido Samira que me apresentara a maioria dos adolescentes do infame grupo de amigos queer da Rocinha. Samira era um pouco mais velha que o resto do grupo e tinha um sorriso muito doce. Relacionava-se com os outros garotos de uma forma quase maternal, embora participasse também da maioria das aventuras do grupo. "Quem vai pra macumba hoje?” - ela perguntava de vez em quando com grande animação. A cada pergunta, várias mãos respondiam agitando-se no ar com vigor.

À medida que nossa conversa continuava até altas horas, o fluxo de pessoas através da área continuava intenso. Havia sempre assunto para fofoca e entretenimento enquanto as pessoas continuavam fluindo diante de nossos olhos. Um grupo de jovens musculosos se reunia perto de onde estávamos sentados e meu amigo Joel ria em tom alto tentando chamar a atenção de algum deles. Um grupo de traficantes armados guardava um cruzamento logo abaixo no mesmo beco, onde várias pessoas se reuniam para fumar e comprar maconha. Os fuzis pareciam ser apenas elementos triviais diante da complexidade de eventos no beco. Ali perto, o bar de jogos eletrônicos funcionava 24 horas por dia e quase sempre estava cheio de fregueses. Diferentes estilos musicais competiam por atenção na área, vindo principalmente dos muitos outros bares

4 De acordo com Censo Demográfico realizado em 2010, apenas 0,3\% da população brasileira declarou praticar uma das religiões de matriz africana. De forma alguma faço um argumento aqui sobre a prevalência geral de apenas dois grupos religiosos na Rocinha, antes, utilizo-me da posicionalidade de meus encontros etnográficos na favela como pontos de imersão para minha análise.

5 Os trabalhos de Patrícia Birman (1995) e Kelly Hayes (201 1), ambos baseados no Brasil, exploram em maior profundidade essa faceta particular das confusões geradas nas ordens de gênero e sexualidade na umbanda, candomblé e, ainda, na chamada "magia negra". 
nas proximidades. Até mesmo os salóes de beleza naquele beco tocavam ritmos do funk para manter a clientela entretida.

Pouco antes da meia-noite, uma mulher mais velha e extremamente magra atravessou o beco usando um vestido longo e de corte simples, plissado da cintura para baixo. Amendoim, um garoto falante, com cabelos longos e quimicamente alisados, olhou para Samira e logo disse: "Oh meu Deus! É aquela mulher de novo!" A tal senhora estava conversando com outra bem ao nosso lado, ambas usavam vestidos semelhantes. Com base naquele código de vestimenta, presumíamos que elas pertenciam a alguma congregação evangélica. A senhora mais magra então tirou um pedaço de papel de uma pequena sacola plástica e mostrou-o à outra senhora com quem estava conversando. Olhando para trás, ela notou nossa presença e virou-se lentamente em nossa direção. Aproximou-se de Samira dando um boa-noite. Samira respondeu com um sorriso. A maioria das pessoas no grupo simplesmente tentava ignorar a presença da senhora. Ela então entregou um panfleto para Samira, contendo versículos bíblicos, e acrescentou: "Todos vocês estão convidados a compartilhar da fé em Jesus na minha igreja, neste domingo, OK?" Samira agradeceu em voz muito baixa. Em seguida, Amendoim murmurou: "Igreja? Eu quero é macumba, meu bem!" A senhora evangélica reagiu levantando as duas sobrancelhas ao mesmo tempo. Ela balançou a cabeça negativamente e respondeu: "Não é hora de você estar na cama, em casa? Você tem que sair dessa vida de rua, meu filho! Sair desse beco, dessa confusão! Onde está sua mãe?" Amendoim rebateu imediatamente: "A única coisa que sei é que você não é a minha mãe para me dar ordens!" A senhora sacudiu a cabeça novamente, não falou mais, simplesmente se afastou de todos nós e logo desapareceu na multidão.

Até onde sabia, nenhum membro do PAFYC era morador de rua, geralmente tinham famílias e casas na favela. No entanto, muitos deles também eram conhecidos por serem extremamente "rebeldes", não respeitavam pai e mãe, ficavam na rua até muito tarde à noite, não obstante os pedidos de suas famílias. No grupo PAFYC, apenas Samira parecia exercer algum grau de autoridade dentre os diferentes membros do grupo. Naquela noite, Amendoim tinha claramente irritado Samira com a forma como respondera à magra senhora. Amendoim havia percebido o mal-estar, então sorriu e simplesmente respondeu: "Tô nem aí para essa porra!" Foi então que Samira deu-lhe um tapa forte na orelha, com sua mão pesada, mas sorrateiramente tentando não rir ao mesmo tempo em que batia.

Antes de sair para a festa, comuniquei à minha vizinha Amélia que estava indo para uma gira de umbanda. Católica devota, Amélia não ficou muito feliz com a notícia e simplesmente respondeu: "Cuidado com essas coisas, hein?" Sorri e pedi que não se preocupasse comigo. Moto-taxis nos levaram até onde era possível subir de motocicleta, daquele local em diante ainda restava uma boa caminhada antes que pudéssemos começar a subir a escadaria final que 
nos conduziria ao terreiro no alto do morro. Do meio da escadaria em diante, já podíamos ouvir o som de tambores vindos de uma pequena casa de tijolos velhos, no meio de uma floresta muito fina. Ao final da subida, Samira estava respirando pesadamente e pediu para fazer uma pausa antes de entrarmos no terreiro. Os outros membros do grupo não prestaram atenção e simplesmente seguiram em frente, deixando-nos para trás. Empurraram o portão de ferro da entrada, que se abriu sem muita resistência, mas repentinamente pararam antes de atravessá-lo. Logo após o portão aberto, havia uma entidade parada, vestida com uma saia vermelha de cetim, com um cigarro aceso entre os lábios e segurando um copo de vinho tinto na mão esquerda.

No chão, a alguns centímetros de distância dos pés descalços da Dama de Vermelho, notei velas queimando em torno de um tridente bastante enferrujado. "Assentamento de Exu", disse Samira, murmurando em meus ouvidos. "Como posso ajudá-los?", disse a senhora fumando. Samira levantou-se rapidamente e caminhou em sua direção, com reverência, tentando resolver a situação um pouco delicada. Educadamente, Samira desejou-lhe um boa noite e, em seguida, disse que estávamos ali para participar da festa de Exu. Alguns momentos tensos de silêncio se seguiram e logo ouvimos um brado: "Mais almas para a festa!", proclamava a entidade, levantando sua taça de vinho em brinde e imediatamente deixando-se cair no chão por sobre seus joelhos dobrados, enquanto emitia uma gargalhada gutural. Pareceu-me assustador. Um pouco mais tarde, mais calma, Samira viria a comentar que essa maneira de rir era típica das pombagiras, nada de preocupante. Disse, ainda, que as pombagiras eram a contrapartida feminina dos exus, por isso gostavam de confusão, assim como eles, que eram considerados os donos das encruzilhadas e os senhores das confusões. Enquanto conversávamos, olhei mais uma vez para o portão, o caminho de saída estava fechado.

No pequeno barracão central, um grande círculo de visitantes estava formado ao redor de médiuns e entidades. Alguns dos exus estavam portando uma capa preta, outros usavam terno, muitos fumavam charutos e quase todos estavam bebendo algum tipo de álcool. Algumas pombagiras presentes eram semelhantes em traje àquela que nos havia saudado no portão de entrada, mas havia uma paleta mais variada de cores. Alguns poucos vestuários eram bem mais elaborados do que outros. Quase todos os presentes moviam-se ao som dos tambores, ainda que muito sutilmente. Um senhor aproximou-se do nosso grupo e ofereceu um pouco da bebida que transbordava de seu copo. Olhei para Samira e ela assentiu com a cabeça: "exu Caveira!" Um dos adolescentes do nosso grupo começou a beber do copo dele. Samira riu e me disse que estava curiosa para ver qual dos nossos amigos iria "virar no santo" primeiro. ${ }^{6}$

6 Nesse contexto, "consubstanciar-se em uma entidade" talvez seja o sinônimo mais preciso para explicar o sentido de "virar no santo" na fala de Samira. 
De repente, uma senhora agarrou a renda externa da própria saia e começou a esfregá-la no corpo de Amendoim, dançando sensualmente. Tonto, ele parecia perder cada vez mais o equilíbrio. Amendoim começou então a segurar a própria cabeça com as duas mãos, puxava os cabelos para cima, tentando colocar um elástico como prendedor. Samira riu e comentou, esfregando suas mãos em agitação: "Essa pombagira é do mal! Viu? Ela vai fazer o Amendoim virar no santo!" Amendoim tentava sustentar a própria cabeça com as mãos, mas ela parecia ficar pesada demais. Samira me disse animada: "Ah, ele está segurando o santo, mas vamos ver por quanto tempo!” Perguntei quando seria a vez de Samira virar e ela soltou uma gargalhada gostosa, respondendo: "Pare! Você já deve saber que isso nunca vai acontecer comigo!"

O ritmo dos tambores havia mudado e o odor de charutos e cigarros aumentava, foi quando outra pombagira começou a falar comigo: "Boa noite, meu menino!" Nunca sabendo exatamente como me direcionar a uma entidade espiritual, respondi timidamente, saudando-a e logo tentando afastar meus olhos dos dela. A pombagira sorriu, cuspiu um pouco de fumaça no meu rosto e passou a falar com Samira, ignorando-me. Uma mulher loira começou a tremer muito, bem ao meu lado direito. Logo estava dando pequenos saltos, movimentando o ar abafado para cima e para baixo. Ao parar e abrir os olhos, ela parecia não entender o que estava acontecendo ao seu redor. Outra pessoa, vestida de branco e muito mais jovem, começou a caminhar rapidamente em nossa direção. Ela estava acompanhando a senhora loira, seu trabalho era cuidar do bem-estar dos médiuns. À medida que as entidades partem deste plano, restam os corpos exaustos dos médiuns, frequentemente bastante confusos. Quando chegam para manifestarem-se, os espíritos geralmente fazem os corpos humanos tremerem violentamente. Apesar de seus esforços, Amendoim não havia conseguido evitar a possessão por muito tempo e estava dançando extasiado pela sala. Pediu a alguém do templo por um copo de vinho e também queria uma saia para vestir. Juntou-se ao grupo de outros exus e pombagiras que estariam dançando, bebendo, fumando e conversando a noite toda.

A fumaça densa que não encontrava saída do barracão, a gargalhada das divindades, as lágrimas de uma menina que se consultava com exu Sete Caveiras em um canto isolado, o brilho intenso das velas que iluminavam um grande altar, o cheiro de suor emanando dos trajes pesados e extravagantes naquela noite quente, todos esses elementos me fizeram sentir bastante confuso. Amendoim tinha acabado de me abraçar, mas ele não mais o fazia como se estivesse saudando um amigo. "Ela é a pombagira Ciganinha!" - Samira clarificou pacientemente. Amendoim não era mais ele mesmo, na realidade, ele era a pombagira Ciganinha. Na festa, havia sido distribuído vinho, também cachaça, em uma abundância impressionante. Samira me disse que estava ansiosa para conversar com a pombagira Dona Rosa, de quem precisava de conselhos. No entanto, essa tal pombagira ainda não havia chegado. Ninguém sabia ao certo 
quando e como ela viria. Contudo, ela veio, ainda que bem mais tarde ao longo do evento. Ela fez o corpo de um garoto negro chamado Edimilson tremer violentamente durante a sua chegada. Dona Rosa chegara quase ao mesmo tempo que os primeiros raios de sol começaram a penetrar através do ar enfumaçado preso no barracão. Naquele momento, Samira começou a tremer um pouco também. Uma possessão inesperada? Samira sorriu e me disse que estava muito ansiosa para consultar-se com Dona Rosa.

Aquela pombagira nos ignorou por muito tempo, fazendo minha amiga ficar ainda mais apreensiva. Eu aconselhei Samira a ir atrás de Dona Rosa. Entretanto, por respeito, ela preferiu esperar por sua vez de conversar com a entidade. Quando Dona Rosa finalmente se aproximou de nós, pegou Samira logo pela mão e a levou para fora da casa. Fiquei um pouco apreensivo, imaginando para onde Samira fora levada. Depois de um bom tempo, Samira voltou para meu lado, trazendo com ela uma lista de materiais que precisava comprar para fazer uma oferenda, a qual deveria ser colocada em alguma encruzilhada entre a favela e o bairro vizinho, de classe média alta, chamado São Conrado. Dona Rosa havia dado instruções exatas a Samira sobre como agradar a Exu e, em troca, obter o que fosse que minha amiga havia pedido.

\section{CONFUSÃO ONTOLÓGICA: \\ EXPERIÊNCIAS E COMPREENSÕES}

Será que eu estava confuso naquela noite por conta das minhas limitações para entender aquela realidade? Ou será que de fato formas definidas de confusão estavam sendo produzidas tanto para mim quanto para outros participantes desse episódio? Foi confusão generalizada ou confusão sob uma forma específica que experimentamos? Se tivesse sido alguma confusão específica, em que contexto surgira? Quais são as ordens mantidas por Exu e Pombagira e quais ordens são desafiadas? Quais as condições de possibilidade para que uma confusão possa emergir de uma forma distinta? Que formas de confusão podem ser particularmente reconhecidas numa festa de umbanda na favela da Rocinha? Quais são as lutas e conflitos de poder que legitimariam a existência de certas confusões? Quais as confusões que certas ordens normativas de classe, sexualidade e religiosidade prefeririam evitar?

As religiões afro-brasileiras floresceram a despeito de um contexto opressivo de escravidão e racismo no país. Na busca de respostas, torna-se importante questionar quais os valores de ordem (e de confusão) que se esperam dos escravizados, descendentes de escravizados e seus aliados no Brasil. Argumento que manter a ordem em uma estrutura de poder em que os negros são confinados aos níveis mais baixos da existência social não é algo de igual interesse para escravizados e para seus algozes. Atualmente, na Rocinha, os praticantes de religiões de matriz africana não podem ser identificados de maneira simplista 
por meio de um determinado grupo racial. ${ }^{7}$ No entanto, a presença histórica de Exu no panteão afro-brasileiro, como o deus de todos os acordos e desacordos, senhor de todos os caminhos e encruzilhadas, mestre de toda a ordem e confusão, parece ter sido profundamente valorizada nas cosmologias das religiões afro-brasileiras, entre outras razões, pelo poder de ruptura que exus e pombagiras oferecem diante de uma ordem social opressiva. Em diferentes partes da África, como no Benim e no Togo, a existência de outras divindades do tipo trickster, em muitos aspectos semelhantes a Exu (que é originalmente uma figura do panteão iorubá), já foi destacada e discutida na literatura antropológica por autores como Augé (1978). Em um texto sobre "inversão de signos", esse autor descreve uma divindade no Togo que é celebrada por "proibir proibições" para suas sacerdotisas, causando assim muita confusão (e ao mesmo tempo prosperidade), desafiando estruturas sociais opressivas, nomeadamente aquelas estruturas relacionadas a dimensões de gênero, no Sudeste do Togo.

No Brasil, há registros históricos sobre a aversão e o medo que os chamados "senhores de escravos" demonstravam em resposta à adoração de Exu pelos negros (Prandi 2001). Até hoje, na Rocinha existe um forte preconceito contra as religiões de matriz africana e seus praticantes, vindo sobretudo de membros de igrejas evangélicas, como era o caso de alguns dos meus vizinhos na favela. Parte da dimensão política que informa atos de reconhecimento da confusão enquanto forma definida se revela quando interrogamos o contexto de ordem contra o qual "uma confusão" pode surgir. Sugiro que grande preocupação é gerada quando o poder de determinar qual confusão pode emergir em uma ordem estabelecida não está mais sob o controle dos interessados em manter o status quo (tratando-se também de classe ou de gênero, por exemplo). Não é surpreendente, portanto, que a existência de Exu como entidade capaz de desafiar estruturas normativas estabelecidas por uma história colonial de opressão e de domínio de valores cristãos tenha levado à demonização de Exu e Pombagira, tanto no Brasil quanto em muitas partes da África (Rodrigues 1935; Souza 1986; Prandi 2001).

Para além do meu sentimento generalizado, uma das formas mais claras de confusão que eu experimentei naquela noite com o grupo PAFYC foi a confusão ontológica de existências que poderiam ser divididas entre divinas e profanas, pela presença de divindades no barracão e a presença de seres que, mesmo como médiuns, também faziam parte da festa enquanto humanos. Acostumado a uma ordem na qual a relação entre o corpo e a pessoa tende a ser mais estável (e até mesmo considerada inextrincável por alguns), era extremamente difícil para mim não ficar confuso quando meu amigo Amendoim já não estava

7 Seria possível argumentar que há muitos evangélicos negros e também praticantes de religiões de matriz africana considerados brancos, por exemplo. No entanto, a "negritude" em questão poderia ser de uma ordem diferente. 
presente na festa, embora seu corpo estivesse dançando bem na minha frente. ${ }^{8}$ Mais confuso ainda era falar com aquele corpo sabendo que era na verdade pombagira Ciganinha quem estava falando comigo. A diferença do vestuário de Amendoim (que usava uma blusa branca, shorts em jeans e chinelos azul claro) e da pombagira Ciganinha (toda vestida de preto e vermelho, usando uma bandana colorida e dançando descalça), certamente, ajudava a entender o processo de transformação. Contudo, embora eu pudesse distinguir Ciganinha e Amendoim em alguns momentos, não era fácil para mim entender que meu amigo não estava mais fisicamente presente, como insistia Samira. De acordo com ela, Amendoim tinha sido transformado em uma outra entidade que não ele. A transformação das vestimentas era necessária, e ajudava meu entendimento da situação, contudo a mudança nesses elementos não se mostrava suficiente para evitar que ocorresse uma forma específica de confusão ontológica (entre corpos, pessoas e outras entidades).

Samira parecia muito mais certa em seus julgamentos sobre quem estava exatamente presente no barracão em um dado momento. Quando exu Caveira possuiu nosso amigo Peterson, por exemplo, ela comentara sem hesitação: "Oh, Peterson se foi!" Ela também parecia ter reconhecido muito mais claramente o momento em que a pombagira Dona Rosa tinha chegado e quando ela tinha deixado o terreiro. Ao mesmo tempo, Samira parecia reconhecer uma outra forma específica de confusão, que eu não tinha identificado muito precisamente. As possessões (ou as transformações) pelas entidades não aconteciam instantaneamente, era comum que os corpos demonstrassem sinais visíveis de transformação por algum período de tempo. Durante este período de transição, mesmo Samira assumia que existia alguma confusão quanto à natureza das entidades que estavam diante de nós. Geralmente, era nessa fase de "limbo" que os corpos tremiam violentamente e a espinha dorsal, as pernas, os braços e até mesmo os dedos dos médiuns começavam a contorcer-se. Além disso, os olhos normalmente se fechavam e as bocas ficavam deformadas. Particular atenção era dada aos médiuns que pareciam sofrer mais durante esse processo de transformação. Quando uma senhora mais velha caiu de joelhos logo atrás de mim naquela noite, foi Samira quem cuidou dela primeiro. Quando outras pessoas correram para ajudar uma moça pálida, Samira se levantou e me disse: "Ela está virando!" Ainda me lembro de ter perguntado: "Virando no quê?" Ao que Samira respondeu: "Como é que vou saber já? Ainda está chegando!" Minutos depois, ouvimos a mesma moça rindo em voz alta e pedindo uma capa e um chapéu. Samira então sabia que tinha sido algum exu que acabara de chegar no barracão. Restava ainda alguma confusão, no entanto, sobre o tipo exato de exu que havia chegado. Essa informação complementar, muitos

8 Para uma discussão mais aprofundada das relações entre corpo e alma, humanidade e corporalidade, em um contexto brasileiro diferente, ver Vilaça (2005). 
não saberiam com certeza até muito mais tarde durante a noite, até que a entidade tivesse dançado um pouco, bebido alguma coisa e então decidisse que estava na hora de apresentar-se ao público presente.

Retomando a discussão sobre inversão de gênero durante o Carnaval no Brasil (DaMatta 1991), nas festas religiosas de matriz africana, as práticas diárias de gênero também parecem sofrer uma certa inversão: em alguns momentos homens vestem-se como mulheres e vice-versa. Além disso, assim como no Carnaval, pessoas com menos escolaridade passam a ser respeitadas como especialistas (especialistas em curas, por exemplo), os pobres tornam-se ricos (portando roupas de rendas caras ou bebendo em abundância). No entanto, é preciso tratar possíveis comparações com muito cuidado, há muitas diferenças importantes entre a confusão que acontece durante o Carnaval e a confusão criada durante os rituais afro-brasileiros. Por exemplo, a forte presença de Exu na cosmologia da umbanda oferece a possibilidade, para os praticantes dessa religião, de atingirem uma transformação muito mais radical da ordem cotidiana. O Carnaval, com seu forte histórico cristão, não parece oferecer possibilidades na mesma dimensão.

Explicitando um pouco mais o argumento acima, para aqueles familiarizados com a umbanda e que reconhecem os poderes transformadores de Exu, a gira não é simplesmente um momento de confusão geral de normas sociais, ou de violação de normas de conduta humanas que continuam válidas, ainda que momentaneamente confundidas. Nas celebrações de Exu, há uma transformação da própria ordem existencial (não apenas semântica) e da própria base epistemológica a partir da qual torna-se possível fazer considerações ontológicas. Por ontologia, entende-se exatamente esse tipo de atenção às questões sobre a existência em si, para além das questões sobre significado ou moralidade. Argumento que há também uma transformação do próprio contexto contra o qual o reconhecimento de uma confusão, como forma definida, pode ser feito. Assim sendo, Amendoim não era, de maneira simplista, um homem vestido como mulher para participar da festa de Pombagira e criar alguma confusão na ordem humana de gêneros. Parece-me mais apropriado considerar as complexidades no argumento dos meus amigos do PAFYC. Portanto, em uma chave menos familiar, devido aos poderes da Pombagira, Amendoim deixa de existir enquanto homem porque ele deixa de existir enquanto pessoa humana - ainda que temporariamente. A transformação aqui não é simplesmente de gênero dentro do espectro da socialidade humana, e sim, mais radicalmente, uma transformação ontológica entre um ser humano e uma entidade de umbanda (ainda que seja uma entidade de gênero feminino). Seria exatamente a atualização dessa possibilidade ontológica produzida na festa de Exu que demandaria o uso de roupas diferentes para a pombagira. Afinal, não se trata de qualquer traje feminino, faz-se necessário portar um traje feminino apropriado para cada entidade específica. 
No Carnaval, a confusão geralmente adquire forma através de pessoas humanas que invertem algumas regras estabelecidas, incluindo regras estabelecidas por entidades divinas, em antecipação à chegada do período da Quaresma. $\mathrm{Na}$ confusão criada nas festas de umbanda, são as próprias entidades que mudam as condições de possibilidade de reconhecimento da existência da ordem e da confusão. Enquanto algumas pessoas experimentam uma sensação de confusão generalizada nesses eventos de umbanda, assim como eu quando comecei a frequentá-los, outros podem estar em sintonia muito maior com as formas específicas de confusão engendradas por Exu e Pombagira. As transformações de ordem efetuadas por essas entidades são diferentes daquelas proporcionadas por pessoas humanas durante o Carnaval. Uma apreciação dessas significativas diferenças na definição e no reconhecimento de confusões é fundamental - uma multiplicidade de confusões específicas, como as que acontecem na Rocinha, merecem tratamento etnográfico detalhado e aprofundado.

Muitos dos meus amigos do PAFYC que estavam comigo naquela festa de Exu na Rocinha, em 2009, entendem que os princípios fundamentais de ordem no mundo em que vivem são passíveis de transformações estruturantes. Mesmo que os seres humanos nem sempre sejam capazes de efetuar tais transformações mais profundas, Exu e Pombagira possuem tal poder. A realização de oferendas, por exemplo, é considerada forma eficaz de agradar essas entidades, na esperança de convencê-las a atualizar uma transformação desejada que talvez estivesse fora do alcance dos humanos. Ao mesmo tempo, meus amigos também explicavam que Exu é o "rei da malandragem", portanto, age de acordo com seus próprios desejos. ${ }^{9}$ Em todo caso, pode-se afirmar que o reconhecimento da existência da ordem e da confusão por parte desse grupo de amigos da Rocinha frequentemente acontecia de maneira diferente da minha (enquanto recém-chegado) e, certamente, de maneira bastante diferente da dos meus amigos evangélicos moradores da mesma favela.

\section{CONFUSÃO DO DIABO}

Evangélicos neopentecostais, a maioria dos meus vizinhos na favela, costumavam fazer uso de uma base epistemológica diferente para considerações ontológicas sobre a confusão. Paizinha, por exemplo, sempre conversava muito comigo na escola onde costumávamos lecionar na Rocinha: eu ensinando inglês e ela português. Ela estava na casa dos 40 anos e tinha duas filhas adolescentes. Por meio de nossas frequentes interações, eu logo comecei a perceber que para Paizinha os fundamentos de organização do mundo eram considerados

9 Embora alguns amigos da Rocinha também afirmassem que Exu não tinha vontade própria, sendo simplesmente o mensageiro de outras entidades. 
verdades absolutas, imutáveis, e reveladas por Deus através da Bíblia. Ao contrário de muitos católicos e dos praticantes das religiões de matriz africana que eu havia conhecido, a maioria dos meus amigos evangélicos na favela simplesmente recusavam-se a celebrar confusões, fossem elas humanas ou não humanas. Particularmente, muitos desses evangélicos não gostavam das celebrações de Carnaval na cidade do Rio de Janeiro e muitos pregavam abertamente contra as confusões que aconteciam no Carnaval. Paizinha e família passaram o Carnaval de 2010 isolados, em um retiro com outros membros de sua Igreja. Nas explicações que davam, argumentavam que as confusões de Carnaval nada mais eram do que pecados, ofensas aos mandamentos da Bíblia. Igualmente pecaminosas seriam as práticas religiosas da umbanda. Descreviam Exu e Pombagira como demônios, ambos reconhecidos como a mesma entidade demoníaca, que se usava de confusão para se fazer passar por entidades diferentes. Do ponto de vista desses evangélicos, as transformações engendradas por Exu e Pombagira eram tão profundamente pecaminosas, que em um dos cultos o pastor as usou como prova da própria existência do mal. Ana Maria, uma professora de escola primária que conhecia, costumava dizer: "Exu? Isso é o Diabo querendo enganar as pessoas! Ele quer se passar como se fosse um deus! Ah, como ele é sujo!" Havia, inclusive, todo um repertório usado por meus vizinhos para identificar e descrever ocorrências de confusões específicas proporcionadas pelo demônio na vida das pessoas. Por exemplo, os chamados "laços do Diabo", armadilhas e confusões preparadas pelo Diabo, eram objeto de grande preocupação e assunto para longas conversas no cotidiano dos meus vizinhos evangélicos.

Existe uma diversidade de considerações epistemológicas a partir das quais diferentes moradores da favela reconhecem confusões específicas. Não estou sugerindo que praticantes das religiões afro-brasileiras são capazes de reconhecer (enquanto existência em si, não apenas enquanto sentido) apenas as formas particulares de confusão proporcionadas por Exu, ou que os meus amigos evangélicos não são capazes de reconhecer e, possivelmente, apreciar algumas formas particulares de confusão. No entanto, muitos desses evangélicos argumentavam que era a Bíblia que deveria determinar a verdade sobre a ordem certa das coisas, ainda que o Diabo tivesse construído uma ordem paralela. Para marcar a diferença de legitimidade entre a ordem de Deus e a ordem estabelecida pelo Diabo, a ordem de Deus era reconhecida como a verdadeira ordem, o resto era apenas uma confusão do Diabo. Grupos diferentes de moradores da Rocinha costumavam recorrer a diferentes repertórios para o reconhecimento de formas concretas de confusão. Com base nas minhas explorações etnográficas, sugere-se que um repertório que pode ser considerado "religioso" possui bastante influência na forma como pessoas diversas são capazes de reconhecer, e de julgar, moralmente, diferentes instâncias de confusão em domínios que ultrapassam em muito o dito "religioso". 
Por vezes, meus vizinhos evangélicos perguntavam-me sobre as minhas incursões em terreiros na Rocinha. Ficavam curiosos sobre o que exatamente eu esperava obter com minhas experiências na umbanda. Certa vez, um dos meus amigos evangélicos me perguntou literalmente: "Vai fazer o que naquela confusão do diabo?" Em outro episódio, ouvi uma velha senhora branca de cabelos negros dizer com bastante raiva e racismo: "Essa tal umbanda é uma bagunça de preto!" No Brasil, há uma famosa composição feita pelo escritor satírico Sérgio Porto em 1968, intitulada "Samba do Crioulo Doido". Escrita durante a ditadura militar no Brasil, a letra desse samba é uma crítica velada de Porto contra a censura do governo militar, que pretendia controlar os temas adequados para as músicas de Carnaval. Em certo período, os militares haviam limitado esses temas a eventos históricos factuais. Em suas letras de música, Porto faz referência a acontecimentos históricos brasileiros factuais, porém ele os combina de forma escandalosamente confusa. Argumentava-se que a música de Porto atendia às exigências de censura do governo militar. Ao mesmo tempo, era notório que as letras eram absolutamente desprovidas de ordem cronológica, o que provocava bastante confusão, a tal ponto que um dos títulos de suas composições terminou permanecendo como parte integrante do repertório brasileiro sobre a confusão: "Samba do Crioulo Doido". Certamente, Porto exibe habilidade admirável ao apropriar-se das normas de um regime ditatorial, em um governo militar, e transformá-las em regras de composição criativa.

\section{LAROIÊ EXU! EXU OMOJUBÁ!}

Mazinho havia me convidado para jantar com ele naquela noite chuvosa. Mesmo andando rápido por entre becos e vielas, terminei chegando um pouco atrasado para nosso encontro. Ele havia esperado por mim paciente e alegre, tratou minha demora como uma situação ordinária. No cardápio para o jantar, arroz branco, carne e alface, com salada de tomates. Fofocávamos sobre o novo namorado da mãe de Mazinho. Ao mesmo tempo, a televisão estava ligada no volume máximo perto de nossa mesa, passando a novela das 8 horas. De repente, o telefone fixo da casa tocou e Mazinho correu para atender à ligação. Ele começou a falar comigo e com a pessoa do outro lado da linha simultaneamente. Fiquei muito confuso, tentando entender o que Mazinho estava falando. Quando desligou o telefone, continuou uma conversa sobre a filha do vizinho que estava grávida. Eu tinha perdido o momento exato em que o assunto havia mudado, o que não parecia ser problema algum para Mazinho. Ele continuava falando. Ele cortou um pedaço de carne malpassada e o levou à boca. No meio de todo o barulho, ainda consegui ouvir o som do garfo caindo no chão. Olhei e nenhum grão havia chegada à boca de Mazinho. Ele parou de falar por um instante, levantou-se de sua cadeira e colocou-se a 
olhar fixamente, muito sério, para o garfo no chão. Bateu palmas estaladas por três vezes seguidas, saudando Exu em reconhecimento àquela confusão. "Laroiê Exu! Exu omojubá!", gritava Mazinho.

Muitos dos meus amigos evangélicos viviam a favela como um lugar cheio de confusões, violações de leis e desvios morais. Portanto, um lugar muito mais perto do Inferno do que do Céu. Enquanto isso, muitos dos meus amigos queer e umbandistas pareciam deleitar-se em confusões que eles reconheciam, e também causavam, em suas vidas diárias. Quando os ordenamentos são potencialmente suscetíveis a transformações, o valor da distinção entre o que conta como práticas normativas e não normativas também pode confundir-se. Muitas vezes, ouvi de membros do PAFYC que morar na Rocinha era muito bom, porque havia movimento, episódios engraçados e muitas confusões. Quando entendidas como parte dos trabalhos de Exu, confusões têm o poder de fazer algumas pessoas (tanto evangélicos quanto umbandistas) reconhecerem a força dos não humanos em suas vidas diárias. Juntamente com esse reconhecimento, surge a oportunidade de lembrar que a existência de confusões é complexa e variada, assim como o são as vidas que coexistem e interligam-se na favela. Por esse e outros motivos, uma exploração etnográfica cuidadosa se faz necessária para ampliar nossa apreciação da dificuldade de lidar com o tema da confusão na antropologia.

\section{BIBLIOGRAFIA}

AUGÉ, Marc, 1978, “Quand les signes s’inversent”, Communications, 28: 55-67.

BIRMAN, Patrícia, 1995, Fazer Estilo Criando Gênero: Possessão e Diferenças de Gênero em Terreiros de Umbanda e Candomblé no Rio de Janeiro. Rio de Janeiro, EdUERJ/Relume Dumará.

DAMATTA, Roberto, 1991, Carnivals, Rogues, and Heroes: An Interpretation of the Brazilian

Dilemma. Notre Dame, IN, University of Notre Dame Press.

HAYES, Kelly E., 201 1, Holy Harlots: Femininity, Sexuality and Black Magic in Brazil. Berkeley, e Los Angeles, CA, University of California Press.

LINO E SILVA, Moisés, 2015, "Ontological confusion: Eshu and the Devil dance to The Samba of the Black Madman", Social Dynamics, 41 (1): 34-46.

PRANDI, Reginaldo, 2001, Mitologia dos Orixás. São Paulo, Companhia das Letras.

RODRIGUES, Nina, 1935, O Animismo Fetichista dos Negros Bahianos. Rio de Janeiro, Civilização Brasileira.

SOUZA, Laura de Mello e, 1986, O Diabo e a Terra de Santa Cruz. São Paulo, Companhia das Letras.

TURNER, Victor, 1967, The Forest of Symbols. Ithaca, NY, Cornell University Press. 
VAN DE PORT, Mattijs, 2007, "Candomblé in pink, green and black: re-scripting the Afro-Brazilian. religious heritage in the public sphere of Salvador, Bahia”, Social Anthropology, 13 (1): 3-26.

VAN GENNEP, Arnold, 1960, The Rites of Passage. Chicago, IL, The University of Chicago Press.

VILAÇA, Aparecida, 2005, "Chronically unstable bodies: reflections on Amazonian corporalities", Journal of the Royal Anthropological Institute, 11 (3): 445-464.

Receção da versão original / Original version

$2017 / 05 / 03$

Receção da versão revista / Revised version $2018 / 09 / 16$

Aceitação / Accepted

$2019 / 01 / 29$ 